\title{
Análise da Dinâmica Espaço-Temporal de Macrófitas SubMersas MAPEADAS COM TÉCNICAS HIDROACÚSTICAS NO RESERVATÓRIO DE TAQUaRUÇU, Rio Paranapanema ${ }^{1}$
}

\author{
Analysis of the Spatial-Temporal Dynamics of Submerged Macrophytes Mapped with \\ Hydro-acoustic Techniques in Taquaruçu Reservoir, Paranapanema River
}

\author{
BATISTA, L.F.A. ${ }^{2,3}$, IMAI, N.N. ${ }^{2}$, ROTTA, L.H.S. ${ }^{2}$, WATANABE, F.S.Y. ${ }^{2}$ e VELINI, E.D. ${ }^{4}$
}

\begin{abstract}
RESUMO - O objetivo deste trabalho foi avaliar o desenvolvimento da vegetação submersa, em termos da altura dos dosséis, considerando as dimensões espaço e tempo, usando técnicas de hidroacústica. Foram realizados dez levantamentos de campo no período de outubro de 2009 a dezembro de 2010, para aquisição de pontos georreferenciados de altura dos dosséis, frequência de ocorrência de vegetação, bem como de profundidade. Medidas limnológicas também foram feitas, a fim de verificar se suas variações poderiam explicar a distribuição espacial das macrófitas. Os dados de vegetação foram analisados por levantamento e por profundidade; além disso, compuseram um banco de dados implementado em um Sistema de Informação Geográfica. Foram então interpolados e das superficies resultantes foram geradas cartas, que indicam a distribuição espacial do crescimento ou decaimento da vegetação. Modelos em três dimensões dos dosséis foram produzidos, para representar a ocupação volumétrica das macrófitas submersas. Os resultados mostraram que houve significativa redução da infestação de um ano para outro. Observou-se, ainda, que os maiores dosséis concentram-se em uma profundidade de 2 a $4 \mathrm{~m}$. O mapeamento identificou tanto áreas de crescimento quanto de decaimento, distribuidas de modo heterogêneo. Não foi possivel observar relação direta das medidas limnológicas com a dinâmica da vegetação, pois não apresentaram variação espaço-temporal significativa. Foi possivel estimar o volume ocupado pelas macrófitas submersas, e a tendência observada é de que o aumento de volume é precedido por uma aparente homogeneização dos dosséis.
\end{abstract}

Palavras-chave: mapeamento, crescimento, volume, sistema de informação geográfica.

\begin{abstract}
The aim of this work was to evaluate the development of submerged vegetation, specifically canopy height, considering space and time dimensions, using hydro-acoustictechniques. Ten field surveys were carried out, from October 2009 to December 2010, to acquire geo-referenced points of canopy height, vegetation occurrence frequency, and depth. Limnological measurements were also made to verify whether their variations could explain the spatial distribution of the macrophytes. The canopy data were analyzed by survey and depth. The data were imported to a Geographic Information System to be interpolated. The generated surfaces were used to build cartographic representations of vegetation growth or decay. Three dimension models of the canopies were also produced to represent the volumetric occupation of the submerged macrophytes. The results showed a significant infestation reduction from one year to the next. It was also observed that the highest canopies have a depth of 2 to $4 \mathrm{~m}$. The mapping identified both growth and decay areas, distributed heterogeneously. No direct relation was detected between the limnological measurements and vegetation growth, since these presented no significant spatial-temporal variation. The volume occupied by the vegetation was estimated, and the trend shows that volume increase is preceded by an apparent canopy homogenization.
\end{abstract}

Keywords: mapping, growth, volume, geographical information system.

Recebido para publicação em 9.12.2011 e aprovado em 15.3.2012.

2 Faculdade de Ciências e Tecnologia, Universidade Estadual Paulista - FCT/UNESP, Caixa Postal 305, 19060-900 Presidente Prudente-SP, Brasil, <ligia@utfpr.edu.br>,<nnimai@fct.unesp.br>,<luizhrotta@yahoo.com.br>,<fernandasyw@yahoo.com.br>;

${ }^{3}$ Universidade Tecnológica Federal do Paraná - UTFPR, 86036-370 Londrina-PR, Brasil, <ligia@utfpr.edu.br >; ${ }^{4}$ Faculdade de Ciências Agronômicas, FCA/UNESP, Caixa Postal 237, 18603-970 Botucatu-SP, Brasil, <velini@fca.unesp.br>.

Planta Daninha, Viçosa-MG, v. 30, n. 2, p. 241-252, 2012 


\section{INTRODUÇÃO}

O crescimento excessivo de macrófitas aquáticas nos reservatórios brasileiros tem gerado problemas de ordem ecológica e econômica. Por um lado, a infestação desequilibra o ecossistema, podendo provocar situações extremas de anoxia noturna ou anaerobiose, quando ocorre mortalidade intensa de macrófitas (Bianchini Junior, 2003). Por outro lado, prejudica a produção de energia elétrica, pois a capacidade de deslocamento que esse tipo de vegetação tem pode levar à obstrução dos equipamentos, uma vez que, flutuando na água, podem-se acumular nas turbinas, causando o entupimento delas (Rocha $\&$ Martins, 2011).

Entre os trabalhos destinados ao estudo da proliferação de macrófitas aquáticas encontram-se abordagens variadas, entre as quais citam-se: levantamento florístico e avaliação da riqueza de espécies (Lolis \& Thomaz, 2011; Martins et al., 2011; Rocha \& Martins, 2011); avaliação visual de níveis de infestação (Martins et al., 2011); investigação dos fatores limnológicos relacionados à ocorrência de macrófitas aquáticas (Carvalho et al., 2005); desenvolvimento de equipamentos para controle (Corrêa et al., 2005); coletas pontuais para determinação de biomassa, a fim de avaliar a cobertura de espécies (Michelan et al., 2010); e uso de técnicas de sensoriamento remoto óptico para identificar ocorrência de áreas colonizadas (Galo et al., 2002).

No que se refere a macrófitas submersas, ressalta-se que há grande dificuldade no processo de obtenção de dados. Uma das formas é por meio de coletas pontuais, com uso de rastelos para inventariar as espécies (Lolis \& Thomaz, 2011). O uso do método do quadro, nesse caso, se restringe a um certo número de elementos amostrais em virtude do trabalho necessário para ser aplicado em grande extensão, quando o objetivo é verificar o nivel de infestação em uma grande área. Ademais, por ser um método destrutivo, prejudica estudos temporais. Outra possibilidade é o uso de imagens de sensoriamento remoto óptico (Malthus \& George, 1997; Yuan \& Zhang, 2008). Entretanto, quando usadas isoladamente, essas imagens apresentam certas limitações para avaliar vegetação submersa, pois são capazes de detectar regiões infestadas apenas até uma determinada altura da coluna d'água, mesmo com imagens de alta resolução espacial $(2,4 \mathrm{~m})$, como observado por Rotta et al. (2011). A dificuldade em detectar vegetação submersa deve-se à atenuação da luz de acordo com a profundidade, reduzindo a energia refletida que poderia ser adquirida pelo sensor (Hestir et al., 2008).

Considerando essas observações, a aplicação da técnica de sensoriamento hidroacústico (Sabol et al., 2002, 2009), com o uso de ecobatímetro, torna-se uma alternativa interessante para mapear a altura dos dosséis de macrófitas submersas. Esse é um dos parâmetros indicadores altamente correlacionados com biomassa, como mostrado por Sousa et al. (2010). Esse tipo de levantamento possibilita caracterizar espacialmente a cobertura da vegetação não apenas em termos de área, mas também com relação à profundidade.

O ecobatimetro baseia-se no princípio da ecossondagem, por meio da qual um pulso acústico é enviado ao meio aquático via um transdutor e os ecos refletidos pelo fundo, por plantas submersas, peixes ou outros elementos presentes na água, são recebidos (Sabol et al., 2002). O tempo entre o envio do pulso e o retorno é utilizado para determinar a profundidade, ou discriminar outras feições, conforme o equipamento. É, portanto, um método ativo de aquisição de dados, fundamentado no principio do SONAR (SOund NAvigation and Ranging), ou navegação e medição de distância pelo som.

Com essa técnica, torna-se possivel a aquisição de dados para mapeamento detalhado dos dosséis de vegetação submersa durante a navegação. Esse levantamento é aplicável a grandes áreas, devendo-se ressaltar que não permite diferenciar espécies. É, portanto, um método ágil de monitoramento da infestação, o qual possibilita avaliar a área colonizada por plantas submersas e a altura dos dosséis - parâmetros necessários para determinar ocupação volumétrica.

Com coletas sucessivas, pode-se caracterizar a distribuição espacial da colonização em uma área ao longo do tempo. Assim, os objetivos deste trabalho foram avaliar a dinâmica espaço-temporal do desenvolvimento da 
vegetação submersa, em termos de altura dos dosséis, e apresentar estimativas do volume ocupado pelas macrófitas submersas.

\section{MATERIAL E MÉTODOS}

A área de estudo situa-se próximo ao município de Santo Inácio (PR), localizada no reservatório de Taquaruçu, no rio Paranapanema, delimitada aproximadamente pelas coordenadas $51^{\circ} 44^{\prime} 42^{\prime \prime} \mathrm{W}, 22^{\circ} 38^{\prime} 10^{\prime \prime} \mathrm{S}$ e $51^{\circ} 43^{\prime} 32^{\prime \prime} \mathrm{W}, 22^{\circ} 37^{\prime} 12^{\prime \prime}$ 'S. O reservatório todo tem área de $80 \mathrm{~km}^{2}$, sendo o segundo maior do rio Paranapanema. A região em que são feitos os levantamentos de dados está ilustrada na Figura 1 e abrange uma área de aproximadamente $1,83 \mathrm{~km}^{2}$, com profundidade máxima em torno de $23 \mathrm{~m}$. A área de estudo situa-se a aproximadamente $32 \mathrm{~km}$, seguindo o curso do rio, da usina de Taquaruçu.

Foram realizados dez levantamentos de campo, no período de outubro de 2009 a dezembro de 2010, com frequência variada, para obtenção de dados dos dosséis e de profundidade com o ecobatímetro.

Os instrumentos utilizados nas coletas em campo foram: duas unidades GPS (Global Positioning System) Garmin, sendo uma acoplada ao ecobatímetro e outra para navegação e apontamento de coordenadas, além de computador portátil para operar o aparelho via software. O modelo de ecobatímetro utilizado foi o Biosonics DT-X, o qual opera com frequências entre 38 e $1000 \mathrm{kHz}$ e pode medir profundidades de até $1.000 \mathrm{~m}$. Foi usado um barco de alumínio com armação metálica para dar suporte ao ecobatímetro, o qual ficava suspenso na água a $0,5 \mathrm{~m}$ de profundidade.

Em cada trabalho de campo, a navegação foi feita em zigue-zague, em um percurso que se iniciava perpendicularmente às margens, indo até profundidades em que o ecobatímetro detectasse a presença de plantas. $O$ trajeto de um dos levantamentos está ilustrado na parte inferior da Figura 1, com pontos verdes para representar ocorrência de vegetação submersa e pontos vermelhos para indicar ausência. Os dados coletados pelo ecobatímetro são representados em um ecograma, como ilustrado na Figura 2, em que se pode observar nas elipses a representação de vegetação submersa. A escala horizontal marca a sequência de pulsos, e a profundidade é vista na escala da direita. A escala da esquerda apresenta a resposta do pulso em decibéis, que é utilizada para discriminar o fundo e a vegetação, ou outros elementos presentes na água.

Após o levantamento dos dados, os ecogramas gerados foram visualizados com o software Visual Analyzer, por meio do qual se verifica a máxima profundidade em que há plantas submersas. Essa informação foi utilizada para processar os dados com o software EcoSAV. Este programa gera um relatório em que cada ponto é identificado com coordenadas de latitude e longitude, profundidade, altura e frequência de ocorrência dos dosséis, com valores calculados por ciclo, formado a cada dez pulsos emitidos. A altura gerada (h) é uma média do ciclo, obtida a partir dos pontos colonizados, e a frequência de ocorrência (f) indica o percentual dos dez pulsos classificados como colonizados. Essas duas medidas foram combinadas para calcular a altura média do dossel (AMD) em cada ponto, conforme proposto por Sabol et al. (2009). Essa grandeza é importante para corrigir casos em que os valores poderiam ser superestimados se usada apenas a medida de altura gerada pelo ecobatímetro, quando poucos dosséis forem detectados em uma área de baixa cobertura. O cálculo da AMD é dado pela equação:

$$
\operatorname{AMD}=(h * f) / 100
$$

A grandeza AMD é usada para caracterizar numericamente os dosséis de macrófitas submersas neste trabalho.

Os dados coletados em cada data foram importados para o SIG (Sistema de Informações Geográficas) Spring (Câmara et al., 1996). Foram então realizados procedimentos de:

a) Cálculo da estatística descritiva dos dados brutos.

b) Interpolação para representação de superficie a partir das amostras coletadas, para cada levantamento realizado, com o método da média ponderada, considerado por Valley et al. (2005) adequado para representação de superfícies de vegetação submersa. O mesmo método foi adotado para gerar a superfície batimétrica, do relevo do fundo 


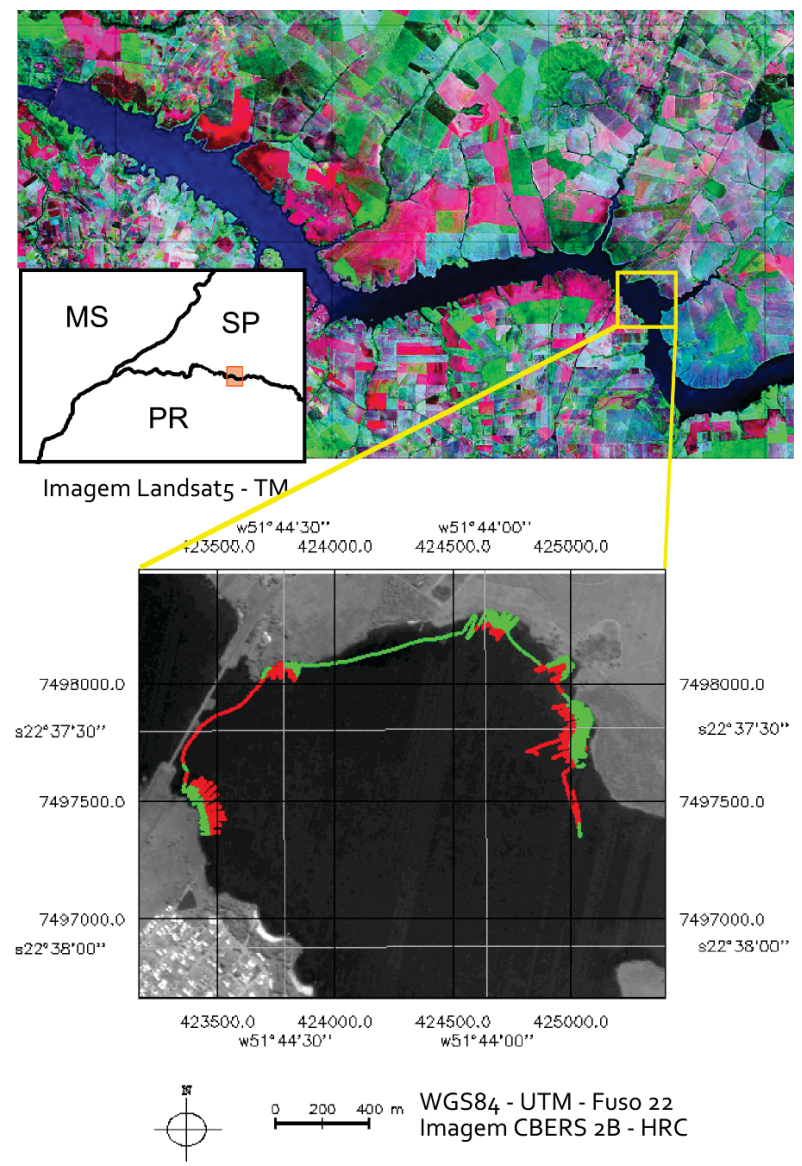

Figura 1 - Área de interesse. do reservatório. O valor de cota de cada ponto da grade regular que representa a superfície é calculado a partir da média ponderada das cotas dos oito vizinhos mais próximos a esse ponto, os quais são ponderados pelo inverso do quadrado da distância. Foram geradas grades com resolução de $2 \mathrm{~m}$.

c) Cálculo do crescimento em cada ponto da superfície, dado pela diferença de AMD entre dois levantamentos sucessivos.

d) Classificação dos planos de informação em faixas de crescimento.

e) Cálculo das áreas de cada classe.

f) Cálculo do volume ocupado pelos dosséis.

\section{RESULTADOS E DISCUSSÃO}

Os resultados da estatística descritiva dos dados brutos estão expressos na Tabela 1. A coluna campo indica como cada levantamento será referenciado a partir daqui neste texto, seguida da data em que foram realizados, do número de pontos amostrais registrados pelo ecobatímetro e das demais estatísticas para a AMD. Nota-se que o número de pontos amostrais é variáve1, pois em alguns levantamentos houve intensa chuva, o que prejudicou

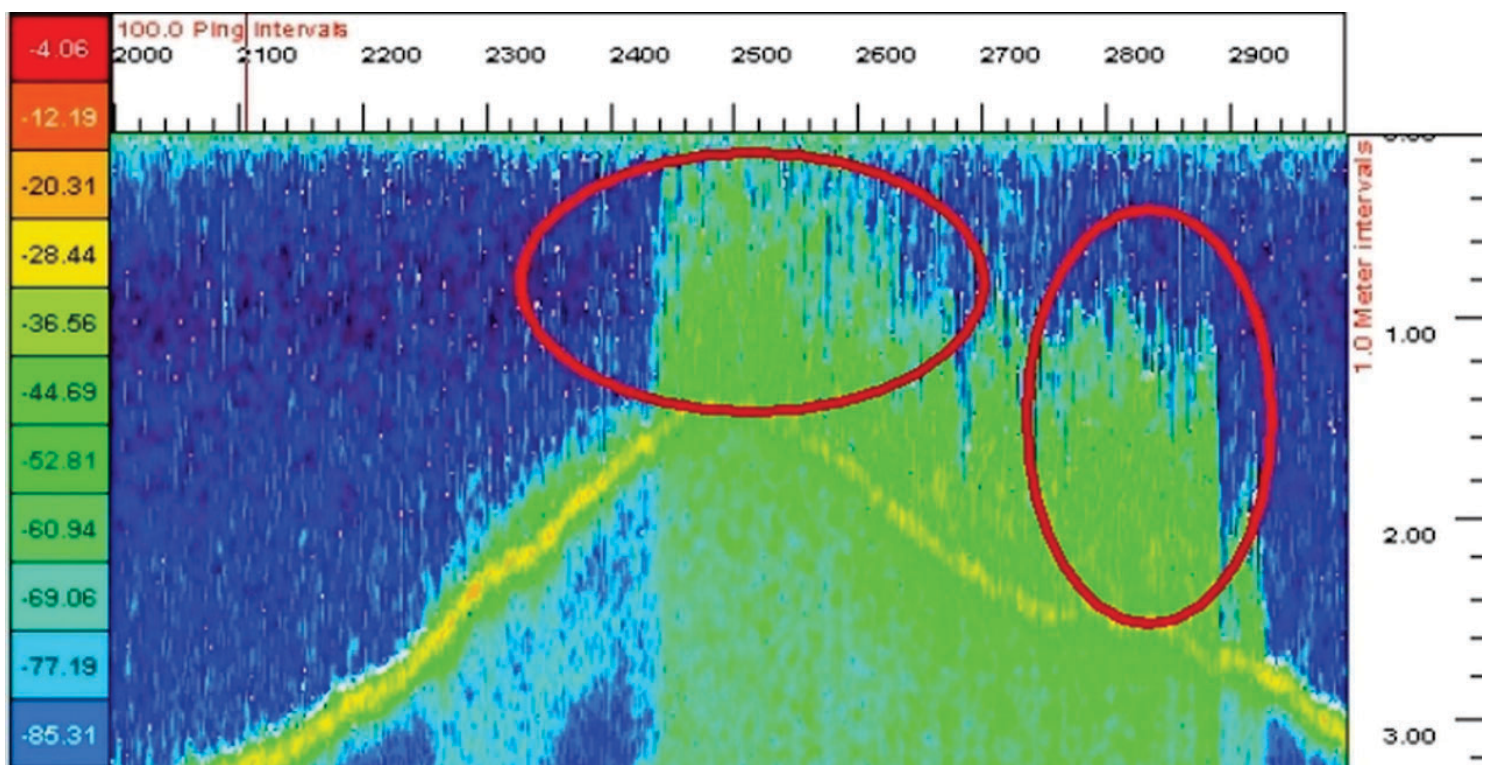

Figura 2 - Ecograma. 
a coleta. Em outras ocasiões, ocorreram problemas com a geração de dados, durante a aquisição (c9) ou durante o pós-processamento (c8).

Os dados da Tabela 1 mostram que a média de altura dos dósseis observados em 2010, a partir de c4, é bem menor que nos três campos de 2009. Nos campos de 2009, a área de estudo estava altamente infestada, com densos bancos de macrófitas presentes na superfície, próximos às margens, como mostra a Figura 3B, C e D. Foram capturadas plantas, flutuando na água, de comprimento maior que $3 \mathrm{~m}$, como apresentado na Figura 3A.

No primeiro campo do ano de 2010, em março, não havia mais infestação em toda a área de interesse. A vegetação reduziu-se drasticamente, alterando regiões antes tomadas por macrófitas submersas, as quais ficaram com remanescentes visiveis apenas nas margens, como ilustrado na Figura 3E. Uma das hipóteses para explicar essa grande redução na cobertura da vegetação é o grande volume de chuva, a qual teria aumentado consideravelmente a turbidez da água e, com isso, reduzido a disponibilidade de luz. Tanto novembro de 2009, cuja precipitação total foi de $268,9 \mathrm{~mm}$, quanto janeiro de 2010 , com precipitação total de $339,9 \mathrm{~mm}$, foram superiores às médias históricas $(131,6 \mathrm{e}$ $216,6 \mathrm{~mm}$, respectivamente para novembro e janeiro), consideradas a partir de 1975, conforme dados obtidos no sítio da Agência Nacional das Águas (ANA, 2011), da estação pluviométrica de Santo Inácio, da SUDERHSA. A vazão do reservatório de Taquaruçu também foi a maior dos últimos dez anos nesse periodo, atingindo pico de mais de $3.500 \mathrm{~m}^{3} \mathrm{~s}^{-1}$, sendo a média a longo termo de aproximadamente $910 \mathrm{~m}^{3} \mathbf{s}^{-1}$. O aumento da vazão acarreta maior velocidade da corrente, o que também explica a redução da vegetação (Biudes \& Camargo, 2008).

O gráfico de boxplot da AMD por campo (Figura 4) ilustra a tendência temporal da evolução da infestação, em que a linha azul une as medianas de AMD de cada campo. Vêse que o pico da infestação foi no $\mathrm{c} 2$, com máximo superior a $1,5 \mathrm{~m}$. A partir do campo c4, grande parte da área colonizada tinha vegetação com AMD não superior a $0,5 \mathrm{~m}$. No c10, embora se observe aumento da AMD, comparando-se aos levantamentos anteriores, não havia sido atingido o mesmo estágio de infestação em comparação ao mesmo mês (c3) do ano de 2009.

\section{Variáveis limnológicas}

Com o intuito de verificar o comportamento espaço-temporal de variáveis limnológicas que pudessem explicar o desenvolvimento da vegetação, foram feitas de três a seis medidas por variável, em pontos distantes entre si, em

Tabela 1 - Dados dos trabalhos de campo

\begin{tabular}{|c|c|c|c|c|c|c|}
\hline Campo & Data & $\begin{array}{c}\text { Número de pontos } \\
\text { amostrais }\end{array}$ & $\begin{array}{c}\text { Mínimo } \\
(\mathrm{m})\end{array}$ & $\begin{array}{c}\text { Máximo } \\
(\mathrm{m})\end{array}$ & $\begin{array}{c}\text { Média } \\
(\mathrm{m})\end{array}$ & $\begin{array}{c}\text { Desvio-Padrão } \\
(\mathrm{m})\end{array}$ \\
\hline $\mathrm{c} 1$ & $30 / 10 / 2009$ & 3.917 & 0,01 & 1,26 & 0,47 & 0,29 \\
\hline $\mathrm{c} 2$ & $13 / 11 / 2009$ & 2.128 & 0,01 & 1,92 & 0,74 & 0,40 \\
\hline $\mathrm{c3}$ & $11 / 12 / 2009$ & 2.085 & 0,01 & 1,35 & 0,40 & 0,29 \\
\hline $\mathrm{c} 4$ & $10 / 03 / 2010$ & 5.368 & 0,01 & 0,72 & 0,27 & 0,14 \\
\hline $\mathrm{c5}$ & $07 / 04 / 2010$ & 6.613 & 0,01 & 0,63 & 0,25 & 0,12 \\
\hline $\mathrm{c6}$ & $23 / 04 / 2010$ & 4.458 & 0,01 & 0,62 & 0,22 & 0,11 \\
\hline $\mathrm{c7}$ & $18 / 06 / 2010$ & 5.502 & 0,01 & 0,56 & 0,19 & 0,11 \\
\hline $\mathrm{c} 8$ & $05 / 08 / 2010$ & 1.065 & 0,01 & 0,49 & 0,18 & 0,10 \\
\hline c9 & $16 / 09 / 2010$ & 2.340 & 0,01 & 0,45 & 0,14 & 0,08 \\
\hline $\mathrm{c10}$ & $01 / 12 / 2010$ & 6.141 & 0,01 & 0,90 & 0,21 & 0,17 \\
\hline
\end{tabular}




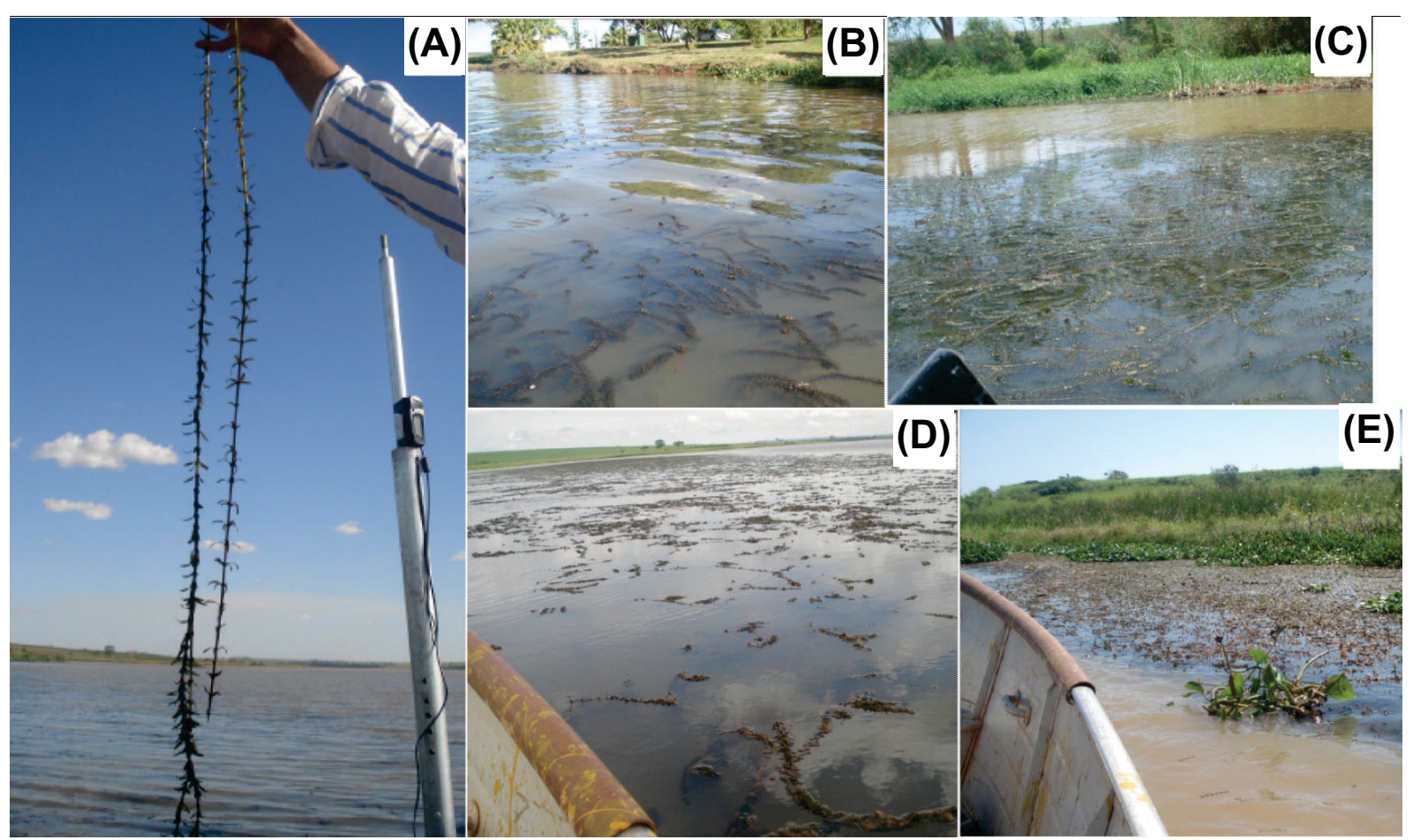

Figura 3 - Fotos obtidas nos trabalhos de campo.

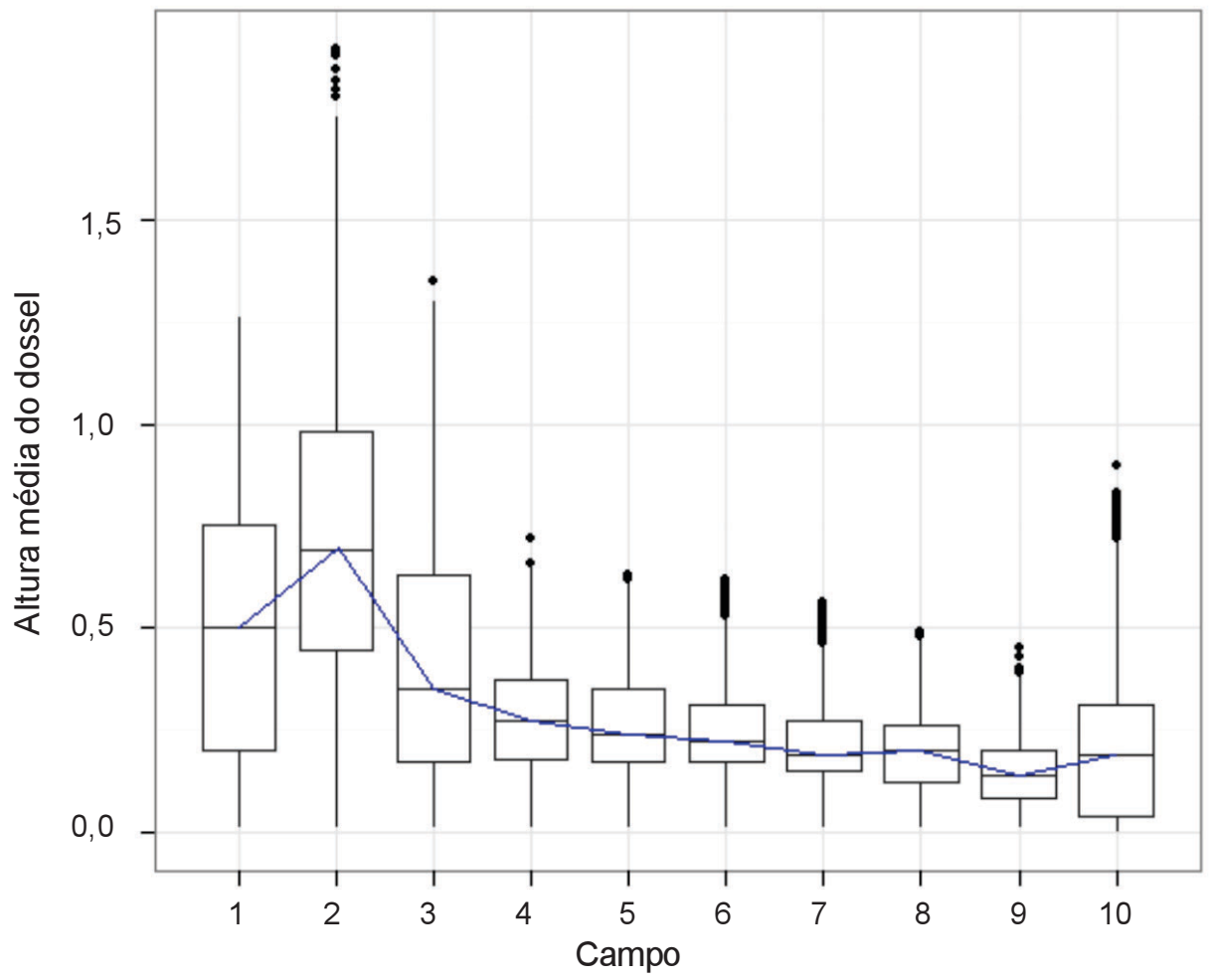

Figura 4 - Boxplot de AMD (m) por campo. A linha azul une as medianas. 
cada levantamento de campo. As variáveis medidas foram: temperatura $\left({ }^{\circ} \mathrm{C}\right)$, transparência $(\mathrm{m})$, com disco de Secchi, oxigênio dissolvido $\left(\mathrm{mg} \mathrm{L}^{-1}\right)$, condutividade elétrica $\left(\mathrm{mS} \mathrm{cm}^{-1}\right)$, turbidez (NTU) e $\mathrm{pH}$. O gráfico da Figura 5 apresenta o coeficiente de variação dos dados adquiridos. O coeficiente de variação é dado pelo desvio-padrão dividido pela média, o qual possibilita comparar a dispersão de variáveis com médias diferentes. Pode-se perceber que, pela Figura 5, cujo gráfico está expresso em porcentagem, com exceção das variáveis turbidez e profundidade do disco de Secchi, as demais possuem o valor desse coeficiente com oscilações de até $10 \%$. Isso mostra que houve pouca variação ao longo do tempo, comprovando a homogeneidade espaçotemporal dessas medidas, o que era esperado, em virtude de se tratar de reservatório, ambiente lêntico (Martins et al., 2011). A variável turbidez é de fato a mais afetada, uma vez que sofre interferências do movimento do barco durante a navegação, sendo influenciada também pela precipitação em dias próximos e até mesmo pela área sujeita à ação do vento (Pierini \& Thomaz, 2009). A transparência medida pelo disco de Secchi também está sujeita a mudanças momentâneas, além da própria visão do indivíduo que está manuseando o disco. Considerando as variações observadas, não se constatou relação direta entre a heterogeneidade espaço-temporal da AMD e as medidas limnológicas.

\section{Profundidade}

A fim de verificar o comportamento temporal da AMD por profundidade, o gráfico da Figura 6 apresenta um conjunto de boxplots organizados por campo (números de 1 a 10) e faixas de profundidade. De modo geral, a faixa de 2-4 m apresenta os maiores valores de AMD em todos os levantamentos, demonstrando que os maiores dosséis não se encontram nas áreas mais rasas. Essa constatação é justificada pelo fato de que em profundidades um pouco maiores, mas que ainda recebem radiação, há mais espaço disponivel para o desenvolvimento das macrófitas submersas. Comparando as faixas de 0-2 m e 4-6 m, vê-se que há predominância de dosséis maiores na faixa mais rasa, nos campos 3, 4 e 9, com grande semelhança entre essas duas faixas nos campos 1 e 2 e maiores dosséis na faixa de 4-6 m nos campos 5, 6, 7, 8 e 10, caracterizando, com isso, certo equilíbrio entre a distribuição dos dosséis nas profundidades de 0-2 e 4-6 m. A faixa de 6-8 m, em geral, apresentou altura de valores baixos, exceto nos campos 1 e 2, em que a área estava altamente infestada.

\section{Crescimento dos dosséis}

Esperava-se que, com a realização dos levantamentos em um período de pouco mais de um ano, poder-se-ia acompanhar um ciclo

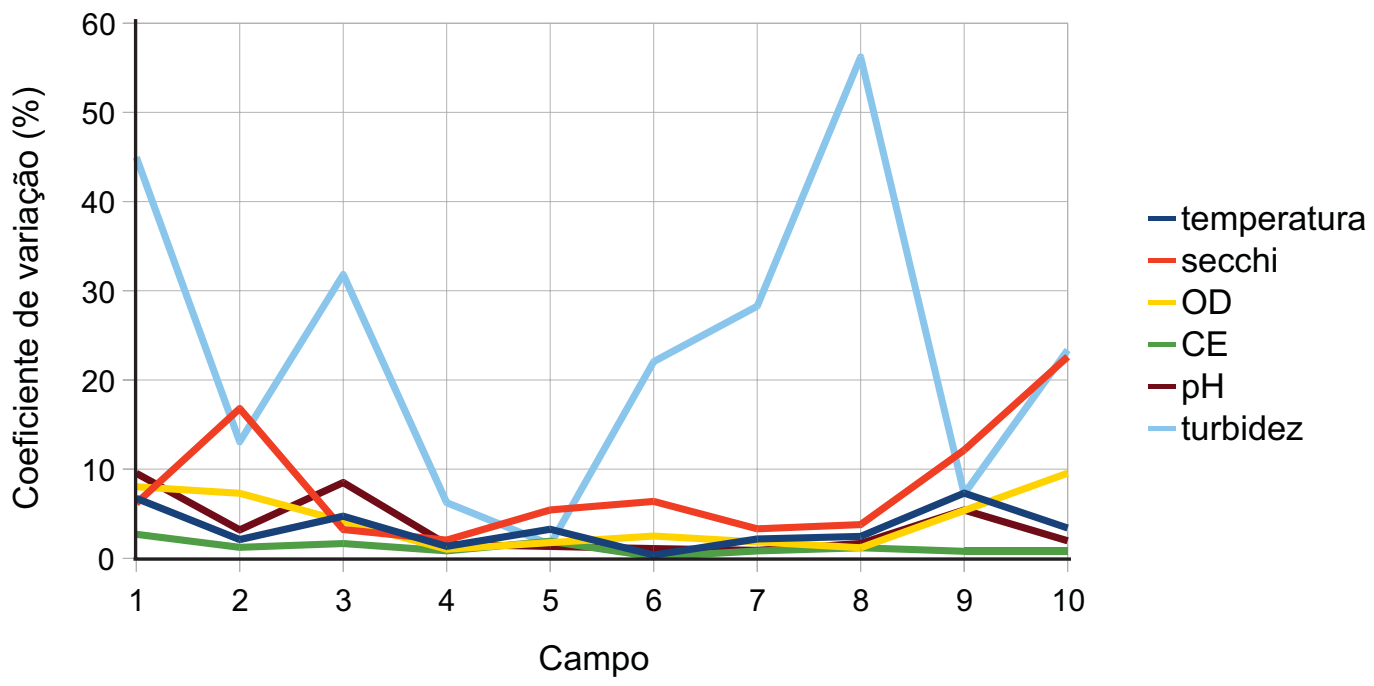

Figura 5 - Coeficiente de variação dos fatores limnológicos ao longo do tempo. 


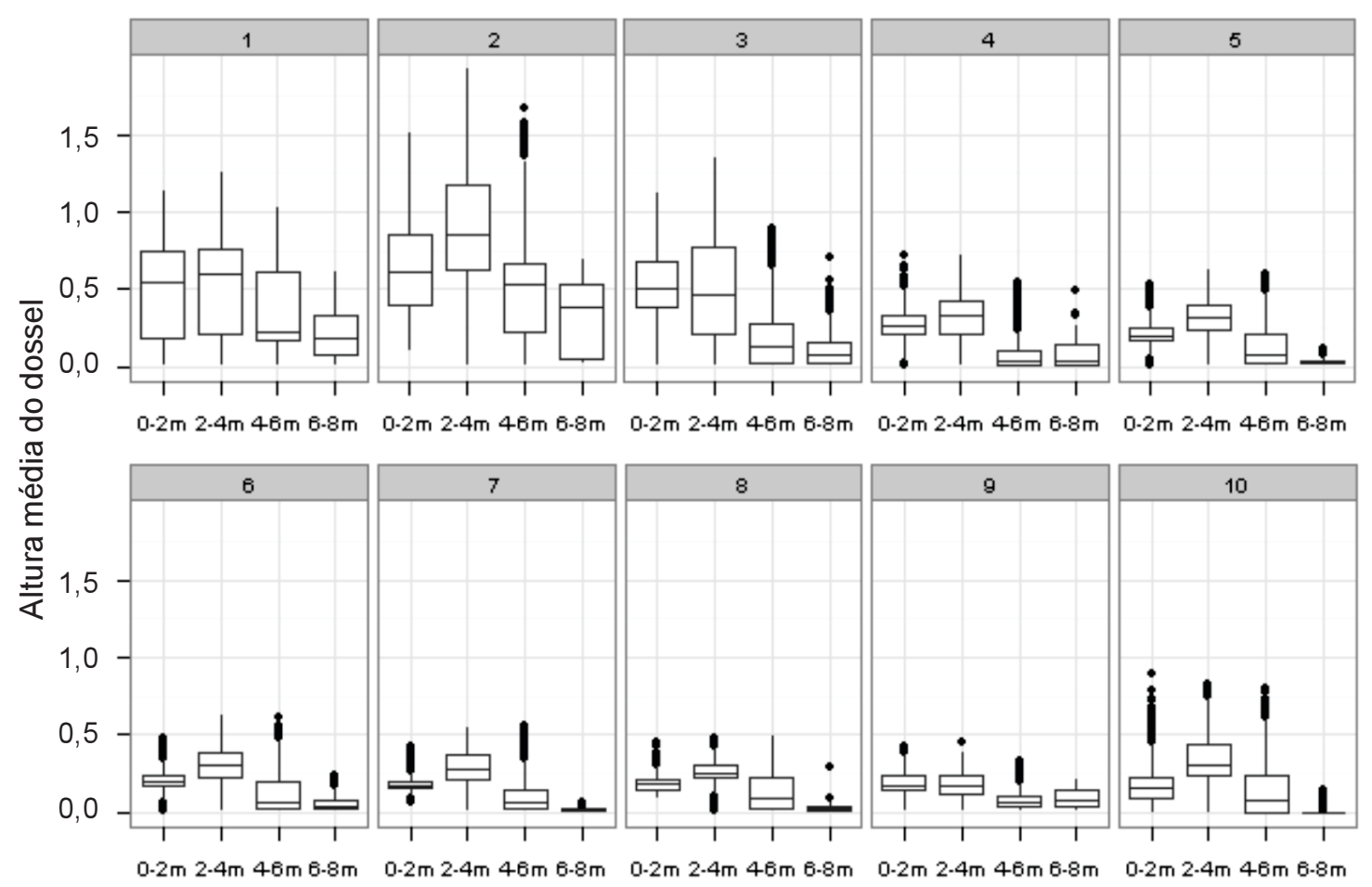

Faixa de profundidade

Figura 6 - AMD (m) por faixa de profundidade em cada levantamento.

completo de evolução das plantas submersas, no sentido de observar variação sazonal que levasse a uma situação final semelhante à situação do início dos levantamentos. Como o volume de chuva foi atípico, bem como a consequente redução da vegetação, também considerada anormal pelos funcionários do condomínio situado às margens do reservatório, delineou-se uma situação em que predominou o decaimento em detrimento do crescimento, com exceção do intervalo c1-c2.

Essa constatação é corroborada pelo gráfico da Figura 7, que mostra os percentuais de área das faixas de crescimento e decaimento para cada intervalo entre dois levantamentos consecutivos. Essa análise por intervalo foi adotada em razão de o crescimento ou decaimento ser calculado a partir da diferença de AMD observada de um levantamento em relação ao anterior, para cada ponto interpolado. No intervalo c1-c2, as áreas de crescimento somadas totalizam pouco mais de $90 \%$ da área colonizada. Já no intervalo c2-c3, pouco mais de $20 \%$ da área registrou crescimento e praticamente o restante apresentou redução, com exceção de um pequeno percentual, que se manteve inalterado. No intervalo c3-c4, o percentual de redução foi ainda maior, com apenas pouco mais de $10 \%$ da área com registro de aumento da altura dos dosséis.

A partir do intervalo c4-c5, pode-se dizer que a situação começou a se modificar, com registro de crescimento para aproximadamente $35 \%$ da área, embora a maior parte ainda fosse de decaimento. Destaca-se o aumento do percentual de áreas sem alteração nos períodos c5-c6, c6-c7 e c7-c8. Ressalta-se que apenas em c9-c10 tem-se novamente maior parte da área em crescimento, com percentual de aumento expressivo (17\%) na faixa de 0,2 a 0,4 .

\section{Distribuição espacial}

Em termos de distribuição espacial, as cartas da Figura 8A-I mostram que, de modo geral, há heterogeneidade espacial de comportamento, pois não se pode separar nitidamente as regiões de crescimento daquelas em decaimento. As cartas da Figura 8 representam 


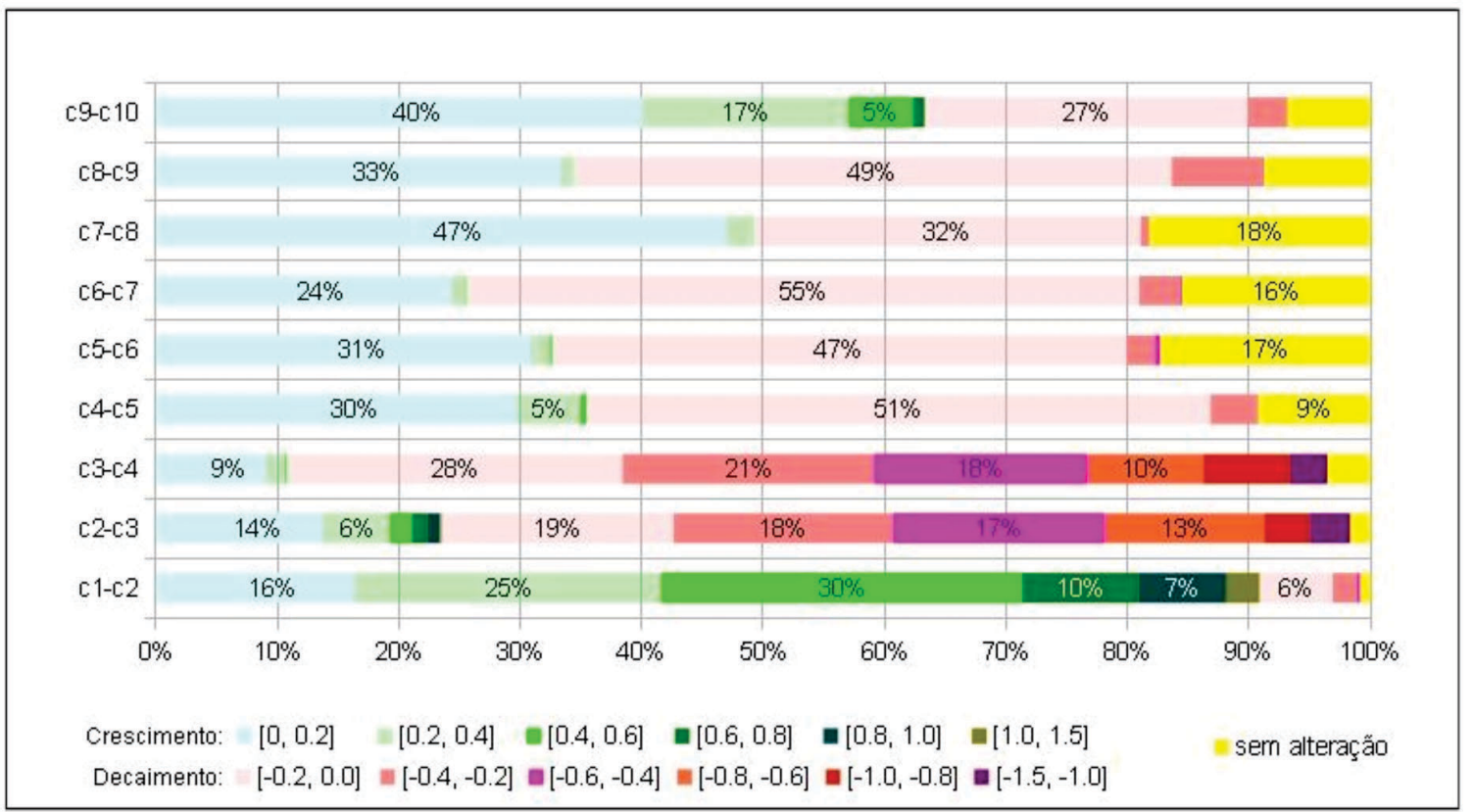

Figura 7 - Percentuais de crescimento por intervalos de campo. Faixas de valores em metros.

apenas uma parte da região de estudo, que ilustra o padrão de toda a área, e as linhas pretas são o indicativo das margens do reservatório. Como essas cartas foram geradas pela diferença entre a superficie interpolada de um levantamento e a do levantamento anterior, apenas áreas coincidentes em dois levantamentos consecutivos podem ser avaliadas, o que justifica a ausência de dados em algumas regiões.

No intervalo c1-c2 (Figura 8A), tem-se predominantemente crescimento dos dosséis, com pequena proporção de decaimento na parte inferior da Figura 8A. No intervalo seguinte (Figura 8B) a situação já é bem diferente em toda a área, com a maior parte caracterizada como decaimento. Na Figura 8C, a proporção de decaimento é ainda maior, atingindo áreas que no intervalo anterior apresentaram crescimento. Na Figura 8D, observa-se nítido crescimento nas regiões mais distantes das margens, com valores nos intervalos de 0,0 a $0,2 \mathrm{~m}$ e 0,2 a $0,4 \mathrm{~m}$. Uma faixa mais larga de decaimento apresenta-se praticamente em toda a margem da Figura 8D. A distribuição espacial do intervalo c4-c5 é a que apresenta a separação mais clara entre áreas de crescimento e decaimento. Enfatiza-se que, na
Figura 8D, o crescimento registrado a uma certa distância da margem indica que os dosséis se desenvolveriam a partir de áreas no limite de profundidade onde a radiação chega, avançando em direção às margens. Nas cartas da Figura 8E-I esse padrão não é mais visivel, mostrando novamente uma distribuição espacial de crescimento e decaimento bastante heterogênea. No intervalo c5-c6 (Figura 8E), visualizam-se pequenas regiões de crescimento na faixa de 0,0 a $0,2 \mathrm{~m}$. Situação praticamente idêntica é observada no intervalo c6-c7 (Figura 8F). O intervalo c7-c8 (Figura 8G) registra extensas e continuas áreas de crescimento, principalmente na parte central, embora haja algumas manchas amarelas, que caracterizam dosséis pertencentes à classe sem alteração. No intervalo c8-c9 (Figura 8H) há poucos dados na região central da carta, pois o equipamento apresentou problemas. Na parte superior da Figura $8 \mathrm{H}$ tem-se a mistura de decaimento com crescimento, este último perto das margens ou no limite das áreas mais profundas. O intervalo c9-c10, da Figura 8I, apresenta crescimento com valores mais altos se comparados aos dos campos anteriores, com algumas classes iguais à da Figura 8A, embora ainda com algumas regiões de decaimento próximas às margens. 


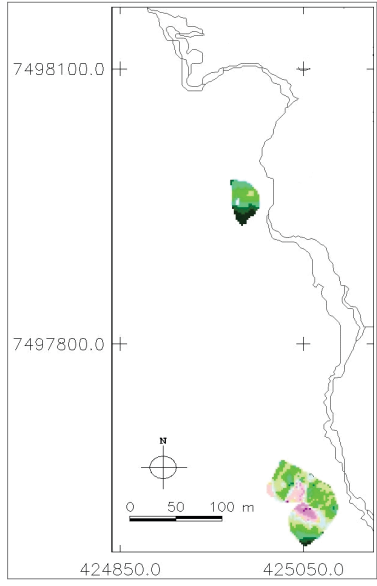

(A) $\mathrm{c} 1-\mathrm{c} 2$

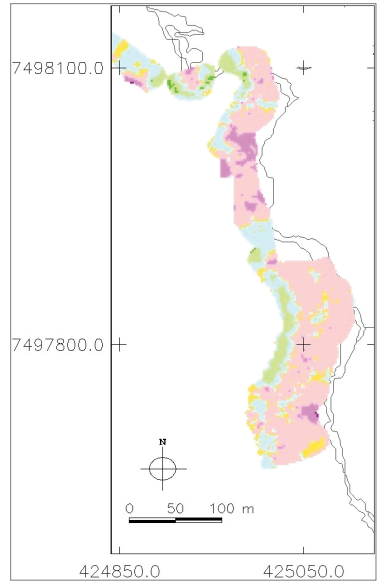

(D) $c 4-c 5$



(G) c7-c8



(B) $\mathrm{c} 2-\mathrm{c} 3$



(E) $c 5-c 6$

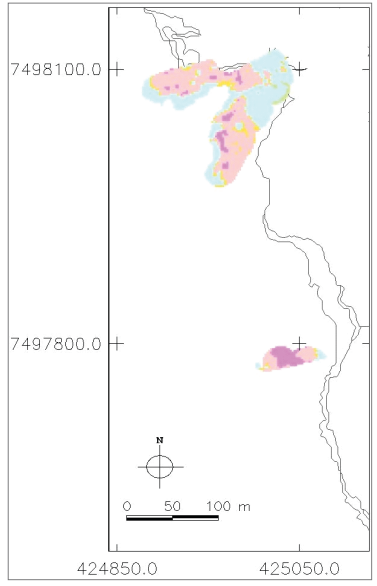

(H) $\mathrm{c} 8-\mathrm{c} 9$

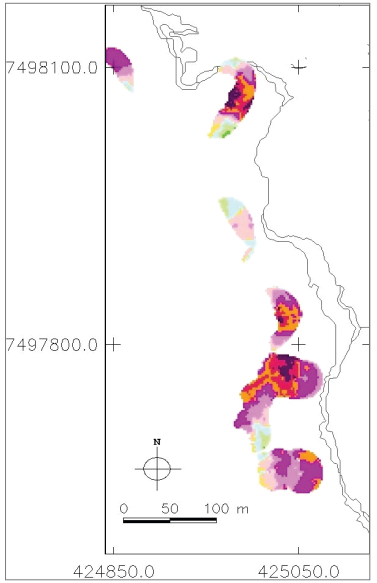

(C) $\mathrm{c3}-\mathrm{c} 4$

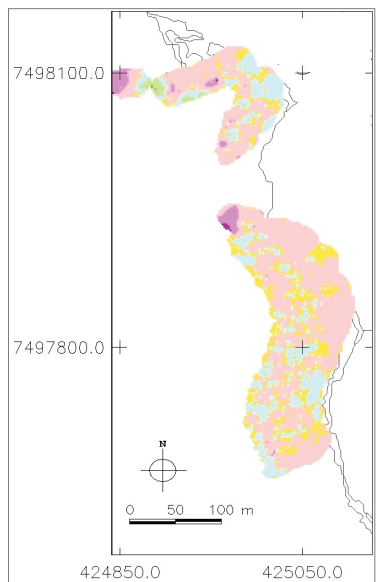

(F) c6-c7

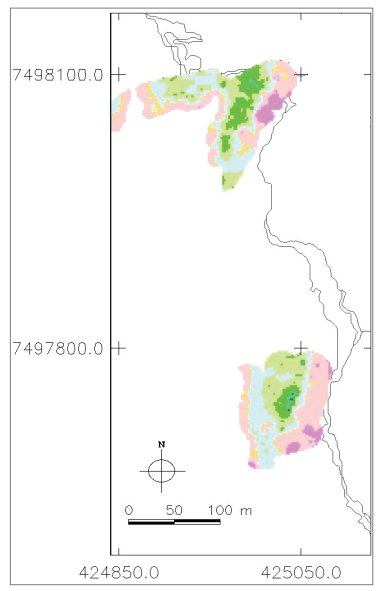

(I) $\mathrm{c} 9-\mathrm{c} 10$

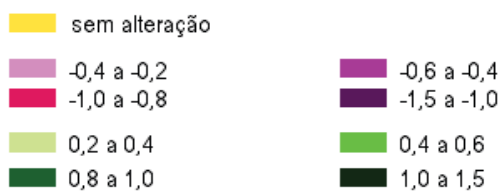

Figura 8 - Cartas de crescimento/decaimento da AMD em cada campo 


\section{Volume}

Com o intuito de avaliar o desenvolvimento da vegetação submersa em termos volumétricos, foi selecionada uma pequena área $\left(8.100 \mathrm{~m}^{2}\right)$ de um intervalo de tempo menor, em que houvesse disponibilidade e coincidência espacial dos dados. O campo c6 foi omitido dessa análise em virtude de sua similaridade e proximidade temporal com c5. A representação em três dimensões dos dosséis está ilustrada na Figura 9, em que as partes $\mathrm{A}, \mathrm{B}, \mathrm{C}, \mathrm{D}$ correspondem respectivamente

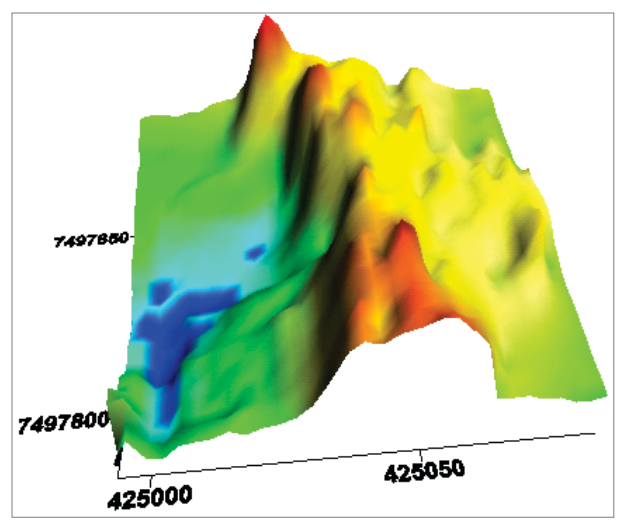

(A) $\mathrm{c} 4$

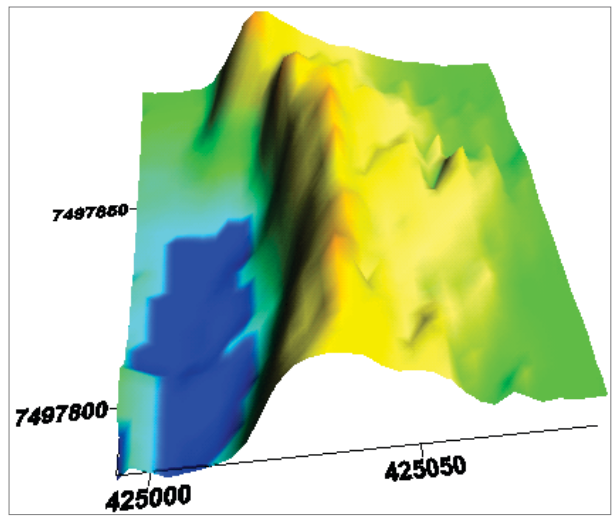

(C) $\mathrm{c} 7$ aos campos c4, c5, c7 e c8, os quais aparentemente tendem a um aspecto suavizado.

De forma geral, observam-se picos mais altos dos dosséis no campo c4, os quais estão um pouco mais baixos no campo c5 e mais uniformes no c7. No c8, chega-se a uma situação bem homogênea, em que a superficie é suave. Essas visualizações conduzem à interpretação de que o crescimento e decaimento observados representariam na verdade $o$ espalhamento horizontal dos dosséis - uma acomodação da vegetação que pontualmente

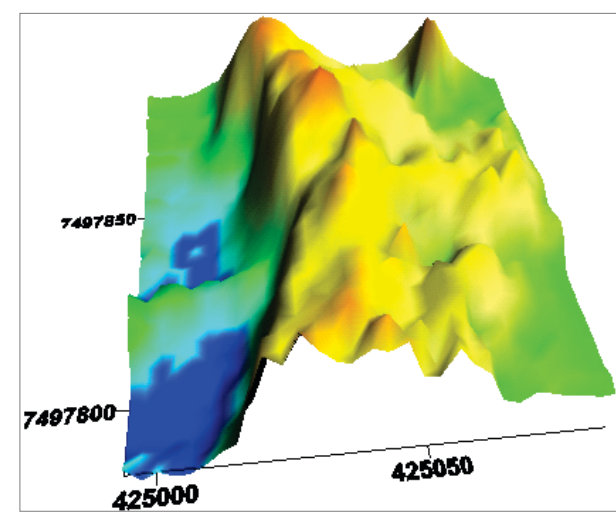

(B) $\mathrm{c5}$

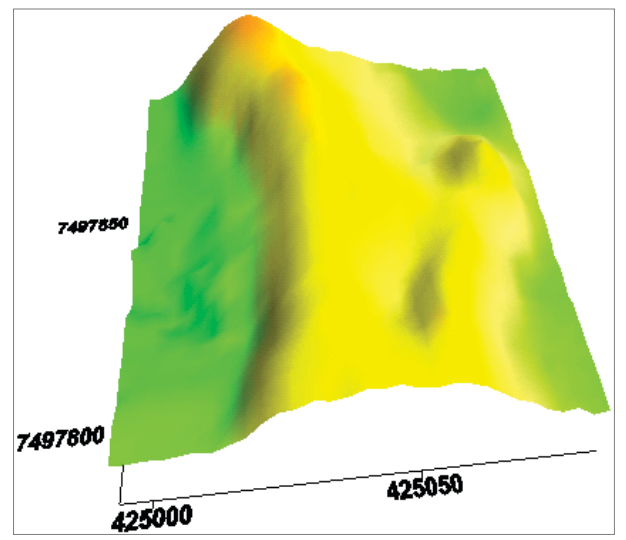

(D) $\mathrm{c} 8$

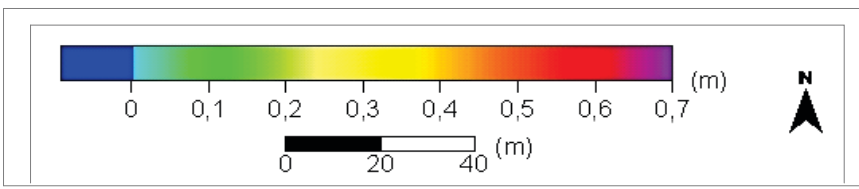

Figura 9 - Superfícies de volume dos dosséis. 
não apresentaria crescimento vertical devido à própria estrutura da planta, que possui caule fino e desenvolve-se de forma emaranhada.

Em termos numéricos, os volumes obtidos para essas superficies, calculados a partir de função disponível no SIG Spring, foram de $1.478,1.428,1.197$ e $1.631 \mathrm{~m}^{3}$, respectivamente para c4, c5, c7 e c8. Esses valores sugerem que o aumento em volume ocorreria quando os dosséis estivessem mais homogêneos entre si, como se tivessem atingido a densidade interna máxima.

Com este trabalho, verificou-se a aplicabilidade do sensoriamento hidroacústico para caracterizar e mapear dosséis de macrófitas submersas, possibilitando monitoramento espaço-temporal e avaliação do volume ocupado pela área colonizada. Enfatiza-se a importância da técnica apresentada para acompanhamento da evolução de infestações, cujas informações podem auxiliar o planejamento e a aplicação dos métodos de controle.

\section{LITERATURA CITADA}

AGÊNCIA NACIONAL DAS ÁGUAS - ANA. Hidroweb: Sistema De Informações Hidrológicas. Disponível em: <http:// hidroweb.ana.gov.br/>. Acesso em: 17 jul. de 2011.

BIANCHINI JUNIOR, I. Modelos de crescimento e decomposição de macrófitas aquáticas. In: THOMAZ, S. M.; BINI, L. M. (Eds.). Ecologia e manejo de macrófitas aquáticas. Maringá: EDUEM, 2003. 341 p.

BIUDES, J. F. V.; CAMARGO, A. F. M. Estudos dos fatores limitantes à produção primária por macrófitas aquáticas no Brasil. Oecol. Bras., v. 12, p. 7-19, 2008.

CÂMARA, G. et al. SPRING: Integrating remote sensingand GIS by object-oriented data modelling. Comp. Graphics, v. 20 , n. 3 , p. $395-403,1996$

CARVALHO, F. T. D. et al. Plantas aquáticas e nível de infestação das espécies presentes no reservatório de Bariri, no rio Tietê. Planta Daninha, v. 23, n. 2, p. 371-374, 2005

CORREAA, M. R. et al. Desenvolvimento de equipamentos para o mapeamento de áreas infestadas por macrófitas aquáticas imersas. Planta Daninha, v. 23, n. 2, p. 269-275, 2005.

GALO, M. L. B. T. et al. Uso do sensoriamento remoto orbital no monitoramento da dispersão de macrófitas nos reservatórios do Complexo Tietê. Planta Daninha, v. 20, n. 1, p. $7-20,2002$
HESTIR, E. L. et al. Remote sensing of environment identification of invasive vegetation using hyperspectral remote sensing in the California Delta ecosystem. Remote Sens. Environ., v. 112, n. 11, p. 4034-4047, 2008.

LOLIS, S. F.; THOMAZ, S. M. Monitoramento da composição específica da comunidade de macrófitas aquáticas no reservatório Luis Eduardo Magalhães. Planta Daninha, v. 29 , n. 2 , p. $247-258,2011$

MALTHUS, T. J.; GEORGE, D. G. Airbone remote sensing of macrophytes in Cefni Reservoir, Anglesey, UK. Aquatic Bot., v. 58, n. 3-4, p. 317-332, 1997.

MARTINS, D. et al. Levantamento de plantas aquáticas no reservatório de Salto Grande, Americana-SP.

Planta Daninha, v. 29, n. 1, p. 231-236, 2011.

MICHELAN, T. et al. Effects of an exotic invasive macrophyte (tropical signalgrass) on native plant community composition, species richness and functional diversity. Freshwater Biol., v. 55, n. 6, p. 1315-1326, 2010.

PIERINI, S. A.; THOMAZ, S. M. Effects of limnological and morphometric factors upon Zmin, Zmax and width of Egeria spp. stands in a tropical reservoir. Braz. Arch. Biol. Technol., v. 52, n. 4, p. 387-396, 2009

ROCHA, D. C.; MARTINS, D. Levantamento de plantas daninhas aquáticas no reservatório de Alagados, Ponta Grossa-PR. Planta Daninha, v. 29, n. 2, p. 237-246, 2011.

ROTTA, L. H. S. et al. Detecção de macrófitas submersas por meio de imagem QuickBird - estudo de caso: Usina hidrelétrica de Porto Colômbia - MG/SP. In: SIMPÓSIO BRASILEIRO DE SENSORIAMENTO REMOTO, 15. 1011, Curitiba. Anais... Curitiba: 2011. p. 4460-4467.

SABOL, B. M. et al. Evaluation of a digital echo sounder system for detection of submersed aquatic vegetation. Estuaries, v. 25, n. 1, p. 133-141, 2002.

SABOL, B. M. et al. Integrating acoustic mapping into operational aquatic plant management: a case study in Wisconsin. Aquatic Ecol., v. 47, n. 1, p. 44-52, 2009.

SOUSA, W. T. Z. et al. Response of native Egeria najas Planch. and invasive Hydrilla verticillata (L.f.) Royle to altered hydroecological regime in a subtropical river. Aquatic Bot., v. 92, n. 1, p. 40-48, 2010.

VALLEY, R. et al. Evaluation of alternative interpolation techniques for the mapping of remotely-sensed submersed vegetation abundance. Aquatic Bot., v. 81, n. 1, p. 13-25, 2005

YUAN, L.; ZHANG, L. Mapping large-scale distribution of submerged aquatic vegetation coverage using remote sensing Ecol. Inf., v. 3, p. 245-251, 2008. 